\title{
Coulisses
}

Revue de théâtre

15 | Hiver 1997

Varia

\section{La biennale de théâtre de Morteau}

\section{Danielle Vingler}

\section{OpenEdition}

Journals

Édition électronique

URL : http://journals.openedition.org/coulisses/5016

DOI : 10.4000/coulisses.5016

ISSN : 2546-9460

\section{Éditeur}

Presses universitaires de Franche-Comté

\section{Édition imprimée}

Date de publication : 1 janvier 1997

Pagination : 21-22

ISSN : 1150-594X

\section{Référence électronique}

Danielle Vingler, «La biennale de théâtre de Morteau », Coulisses [En ligne], 15 | Hiver 1997, mis en ligne le 26 avril 2019, consulté le 31 octobre 2019. URL : http://journals.openedition.org/coulisses/ 5016 ; DOI : 10.4000/coulisses.5016

Ce document a été généré automatiquement le 31 octobre 2019

Coulisses 


\title{
La biennale de théâtre de Morteau
}

\author{
Danielle Vingler
}

À quelques kilomètres de notre capitale Franc-Comtoise, dans cette petite ville aux confins de la Suisse se déroule un événement théâtral qui mérite qu'on parle de lui : la biennale de théâtre de Morteau.

1 Cette manifestation, la $9^{\text {ème }}$ du genre, regroupe tous les deux ans une quinzaine de troupes de théâtres amateurs et professionnels françaises et étrangères. Elle fidélise un public local nombreux qui suit avec intérêt jusqu'à trois ou quatre spectacles par jour, mais aussi des habitués pour la plupart Suisses ou Bisontins.

Cette année le théâtre « étranger » a pris des couleurs européennes avec la présence de l'Allemagne, de l'Italie et de la Principauté de Monaco. La Suisse est accueillie chaque année en voisine mais également le Québec. Dans un passé déjà lointain, la troupe organisatrice (club Théâtre de la MJC) «est tombée en amour " selon l'expression consacrée outre Atlantique, avec ses lointains cousins.

Cette année encore le programme était éclectique : créations, théâtre contemporain, théâtre classique (cf. programme). Les créations sont nombreuses et ne craignent pas d'aborder des genres peu traités comme le théâtre de sciences ou des sujets tabous comme la grande vieillesse.

Si l'ouverture de la Biennale avec Goldoni et sa clôture avec l'intervention de la Brigade du Bien-Être tirent cette manifestation vers la bonne humeur, une place importante est faite au devoir de mémoire et à l'émotion avec les pièces de J.C. Grumberg et d'A. Mnouchkine.

La prestation québécoise est toujours très attendue. Il souffle à cet instant, peut-être à cause de l'accent et du vocabulaire, même s'ils sont devenus presque familiers, comme un vent d'une culture d'au-delà des océans, et au plaisir se mêle la nostalgie de ne pouvoir aller y regarder de plus près...! 


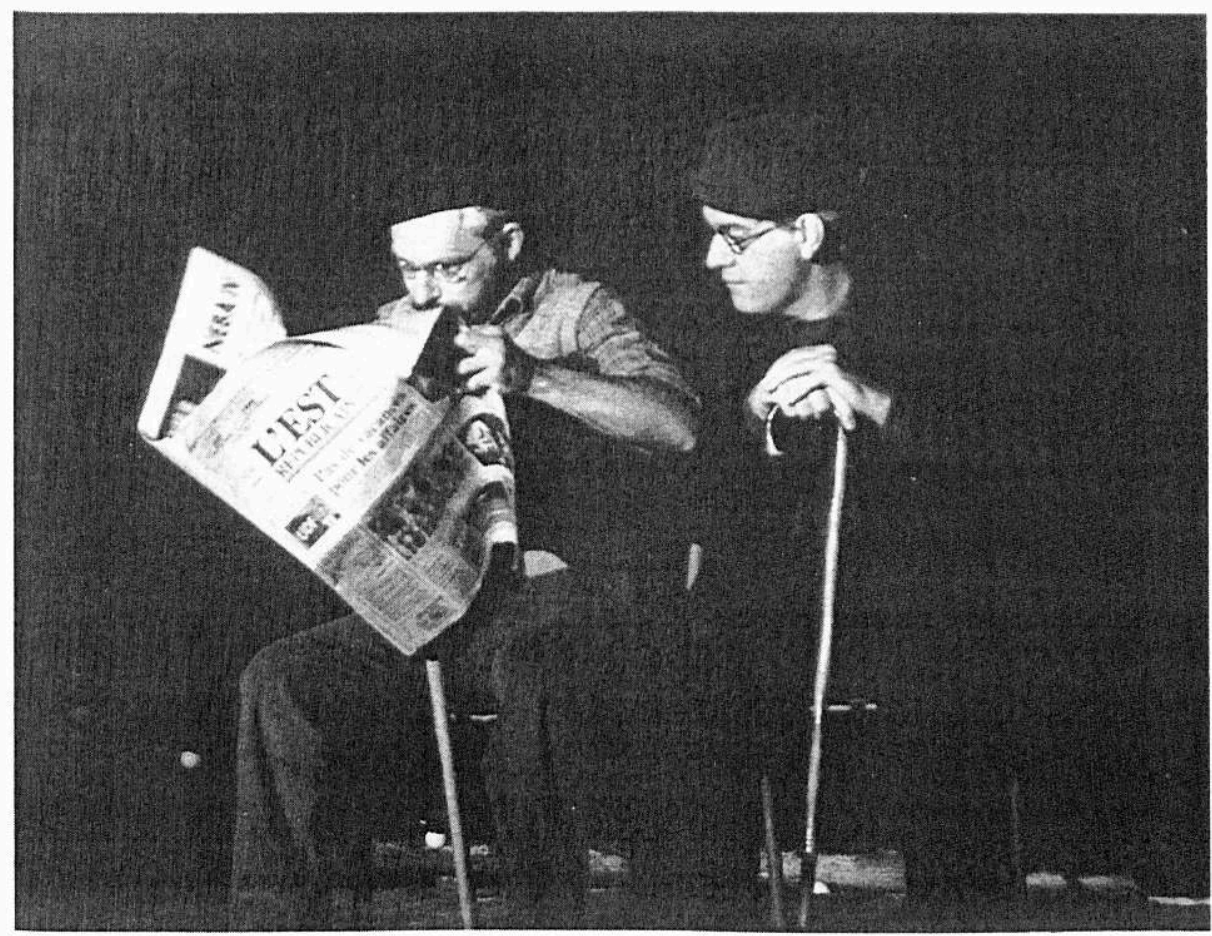

Cliché MJC Morteau

2 Co-organisateurs des Rencontres de Théâtre Amateur, les Directions Régionale et Départementale de la Jeunesse et des Sports, le Club Théâtre de la MJC et la Ville de Morteau, devant le succès de ces manifestations, décident dès 1984 d'élargir leur partenariat à la Direction Régionale des Affaires Culturelles, pour ouvrir leur programmation à quelques manifestations professionnelles.

Toujours dans un souci d'ouverture la dimension francophone puis internationale est abordée dès 1986 avec le soutien du Conseil Régional, de l'Office Franco-Québécois pour la Jeunesse, de l'Association Franche-Comté Échanges Internationaux.

Forte de son succès, la Biennale s'intégra dès 1994 dans la politique culturelle du District de Morteau qui lui consacre une ligne budgétaire, et dans celle de la ville de Morteau qui en 1997 réaménagera son théâtre municipal afin d'offrir les meilleures conditions d'accueil aux comédiens et au public.

\section{ANNEXES}

Programme de la 9ème Biennale de Théâtre de Morteau, du 15 au 19 mai 1996. 
Mercredi 15 mai

Les Cancans de Goldoni

Atelier Théâtre MJC Morteau

Jeudi 16 mai

Équations - création TUFC ; Besançon

Méphisto d'Ariane Mnouchkine ; Théâtre St Jean de Maurienne

Les compépères - création J. Bogar - A. Monnot ; Villers le lac

Macbett de Ionesco, Atelier du Verseau ; Salins

Vendredi 17 mai

L'opéra de la Lune de Prévert, Théâtre du Bambou ; Beaune

Le Magichien - Cie Graines de Clown ; Besançon

Une sortie à la campagne et trois malheureux d'A. Petito Théâtre de Salerne (Italie)

Les sœurs Donahue de G. Aron, Studio de Monaco

Samedi 18 mai

Les touristes - Brigade d'intervention; Montbéliard

La Brigade du Bien-être - Théâtre de l'unité ; Montbéliard

Les compépères - création J. Bogar- A. Monnot ; Villers le lac

Parfois, j'ai des problèmes partout de N.M. Holz ; Allemagne

La déposition d'H. Pedneault, Théâtre au Noir ; Montréal (Québec)

Nuit des comédiens - Conteurs du Pays de Chaux

Dimanche 19 mai

Sur le matelas de M. Garneau, Création - Cie les Cormorans ; Montréal (Québec)

L'atelier de J.C. Grumberg - Cie du Trac-n-art ; Lausanne (Suisse) 